\title{
Effect of toothbrushing with different manual toothbrushes on the shear bond strength of orthodontic brackets
}

\section{Guilherme José Pimentel Lopes de Oliveira(a) \\ Chaine Pavone(a) \\ Maurício Ribeiro Costa(b) \\ Rosemary Adriana Chiérici Marcantonio(c)}

(a) MS Graduate Student; (b) PhD; (c) Professor Department of Diagnosis and Surgery, Division of Periodontology, School of Dentistry at Araraquara, São Paulo State University, Araraquara, SP, Brazil.

\section{Corresponding author:}

Guilherme José Pimentel Lopes de Oliveira UNESP - Faculdade de Odontologia de Araraquara

Departamento de Periodontia

Rua Humaitá, 1680

Araraquara - SP - Brazil

CEP: 14801-903

E-mail:guioliveiraodonto@hotmail.com

Accepted for publication on Mar 19, 2010

Received for publication on May 21, 2010

\begin{abstract}
The aim of this study was to evaluate the effect of brushing with a Colgate $360^{\circ}$ or Oral B Indicator 35 toothbrush on the shear bond strength of orthodontic brackets bonded to extracted human teeth. The bristle wear and bristle tip morphology were also examined after simulated tooth-brushing. Orthodontic brackets (Roth-P/ $1{ }^{\text {st }}$ and $2^{\text {nd }}$ premolar S/D- Slot 0.18 ") were bonded (Transbond $\mathrm{XT}^{\circledR}$ ) to the smoothest surface of each of 45 extracted human molar and premolar teeth. Test specimens were randomly divided into three groups: Group 1, control group with no brushing; Group 2, brushing with the Oral B Indicator 35; Group 3, brushing with the Colgate $360^{\circ}$. Samples were adapted to a machine that simulated tooth-brushing. The bond strength of each bracket to each tooth was assessed with a mechanical testing machine. The bristle wear and bristle tip morphology indices were also assessed. Statistically significant differences were defined for $p \leq 0.05$. The average bond strengths (range: $90.18-90.89 \mathrm{kgf} / \mathrm{cm}^{2}$ ) did not differ among the three groups. The Colgate $360^{\circ}$ showed less bristle wear and a better bristle tip morphology than the Oral B Indicator 35 toothbrush. However, use of either toothbrush did not decrease the bond strength of the orthodontic brackets. Therefore, patients undergoing orthodontic therapy can safely use either toothbrush.
\end{abstract}

Descriptors: Toothbrushing; Orthodontic brackets; Primary prevention.

\section{Introduction}

The role of plaque accumulation in the pathogenesis of caries and periodontal disease is well-established. Disease prevention and treatment are based mainly upon biofilm removal. The most economic, practical, and accessible method for biofilm removal is personal tooth-brushing and auxiliary means. ${ }^{1}$ However, patients undergoing orthodontic therapy face great difficulties in applying oral hygiene methods. The orthodontic apparatus includes bands, brackets, and arches that act as barriers, not allowing toothbrush bristles and auxiliary cleansing to reach the underlying tooth surface. This situation induces biofilm formation, favoring gingivitis and caries formation..$^{2,3}$

Various changes have been promoted in the orthodontics field in the last 50 years. One major change was the replacement of the mouth overall bandage technique by direct bracket-bonding to the dental enamel. 
This change simplified the installation of fixed appliances and allowed for a shorter period of orthodontic treatment. ${ }^{4}$ However, it is introduced the risk of bracket detachment, which can lead to treatment delays and increased costs. ${ }^{5}$ The bond strength of the bracket is also potentially affected by the friction generated during tooth-brushing. ${ }^{6,7}$ The frictional force of toothbrushes on orthodontic brackets may alter the bristle morphology through wear. Worn toothbrushes reduce biofilm removal during brushing. ${ }^{8,9}$ Round-tipped bristles are recommended to prevent damage to gingival tissues ${ }^{10}$ with other shapes being associated with abrasions at the cement-enamel junction ${ }^{11}$ and gingival recessions. ${ }^{12}$ These factors are important in determining when to replace an old toothbrush with a new one.

The aim of this study was to assess whether brushing with a Colgate $360^{\circ}$ or Oral B Indicator 35 toothbrush alters the bond strength of orthodontic brackets fixed to extracted human teeth. We also assessed the wear of the bristles and bristle tips after two years of simulated brushing.

\section{Material and Methods Sample preparation and experimental conditions}

Forty-five extracted human premolar and molar teeth were used in this study, which was approved by the Ethical Committee (CEP-12/06). As selection criteria, the teeth had to be intact and free from restorations, caries, or root wear. The surfaces of each tooth were polished with rubber cups and non-fluorided prophylactic paste for $20 \mathrm{~s}$, simulating a recent cleaning. Afterwards, orthodontic brackets (Roth$\mathrm{P} / 1^{\text {st }}$ and $2^{\text {nd }}$ premolar S/D- Slot 0.18"; Dental Morelli Ltda., Sorocaba, São Paulo, Brazil) were bonded to the flattest surface of each tooth. The material used to bond the brackets was a BIS-GMA resinous system (Transbond $\mathrm{XT}^{\circledR}, 3 \mathrm{M}$ Unitek, Monrovia, California, USA) that was light-polymerized using an Ultralux appliance (Dabi Atlante, Ribeirão Preto, São Paulo, Brazil). A single researcher performed bonding following the manufacturer's instructions.

After bonding, samples were individually stored in glass jars containing $5 \mathrm{ml}$ of distilled water and maintained at $37^{\circ} \mathrm{C}$. They were then stabilized in an auto-polymerizing acrylic resin (VIPI Cril, Pirassununga, São Paulo, Brazil), made using a metal matrix designed for this study, to obtain 45 test specimens. The test specimens were randomly distributed into three groups: Group 1, control group with no brushing; Group 2, brushing with the Oral B Indicator 35 toothbrush (Oral B, Cincinnati, Ohio, USA); and Group 3, brushing with the Colgate $360^{\circ}$ toothbrush (Colgate-Palmolive, New York, NY, USA). Samples were adapted to a brushing machine, projected by the discipline of removable partial denture of Foar-Unesp (Araraquara, São Paulo, Brazil) (Figure 1) that simulated a two-year brushing period with a force of $200 \mathrm{~N}$, frequency of $10 \mathrm{RPM}$, and 20,000 cycles of brushing movements. ${ }^{13}$

\section{Analysis of bracket bond strength}

After the brushing stage was completed, the test specimens were adapted to new auto-polymerizing acrylic resin blocks. The bond strength was evaluated with a mechanical testing machine (Material Test System, MTS 810, Minneapolis, Minnesota, USA), operated by a trained, blinded researcher. The machine speed was set at $1.0 \mathrm{~mm} / \mathrm{min}$, the recording speed was maintained at $20 \mathrm{~mm} / \mathrm{min}$, and the scale was set at $50 \mathrm{~kg} .{ }^{7}$ The force needed to disrupt the orthodontic bracket bond was verified for each sample.

\section{Analysis of brush bristles}

After brushing simulations, 30 toothbrushes (15 Colgate $360^{\circ}$ and 15 Oral B Indicator 35) were assessed for bristle wear and bristle tip morphology. Ten new toothbrushes (5 Colgate $360^{\circ}$ and 5 Oral B Indicator 35) were assessed as a pre-brushing reference.

Bristle wear analysis was performed according to the methodology used by Rawls et al. ${ }^{14}$ (1989). Five measurements were recorded for each toothbrush using a digital pachymeter (Series 500-144B, Mitutoyo, Suzano, Brazil). The measured parameters were the Free-long-length (FLL; length of the toothbrush head on the upper part on the larger side), Base-long-length (BLL; length of the toothbrush head on the lower part/base on the larger side), Front free length (FFL; length of the toothbrush head on 


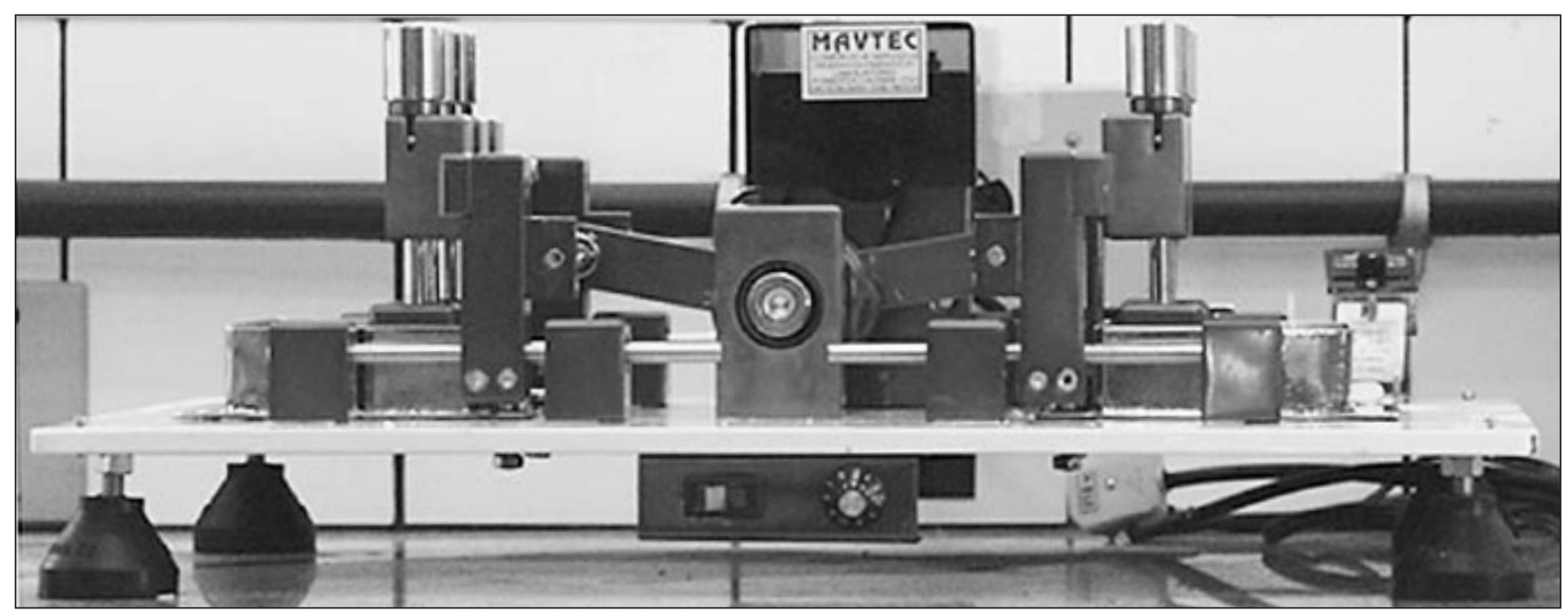

Figure 1 - Brushing Machine.

the upper part on the smaller side), Base free length (BFL; length of the toothbrush head measured on the lower part/base on the smallest side), and Bristle length (BRL; bristle height measurement). The wear index (WI) was calculated by:

$$
\mathrm{WI}=\mathrm{FLL}-\mathrm{BLL}+\mathrm{FFL}-\mathrm{BFL} / \mathrm{BRL}
$$

For the bristle tip analysis, four images of each toothbrush were obtained at $20 \times$ magnification using an optical microscope (Leica Reichert \& Jung Products, Wetzlar, Henssen, Germany). The images included 2 top views and 2 side views to assess the central and side bristles, respectively, in randomly chosen areas. A trained, calibrated, and blinded examiner performed two readings of the toothbrush bristles (Kappa Index $=0.83$ ), using the bristle tipgeometric index ${ }^{10}$ (Figure 2).

\section{Statistical analysis}

Bioestat 5.0 software (UFPA, Belém, PA, Brazil) was used for statistical analysis. To analyze the shear bond strength of the bracket to the tooth, the Kruskal-Wallis test was used with the Mann-Whitney test. To analyze bristle wear before and after brushing, the paired $t$-test was used. The MannWhitney test was used to compare the bristle tips between the two toothbrushes. The Wilcoxon test was used to assess the bristle tips before and after brushing within the same group of toothbrushes.

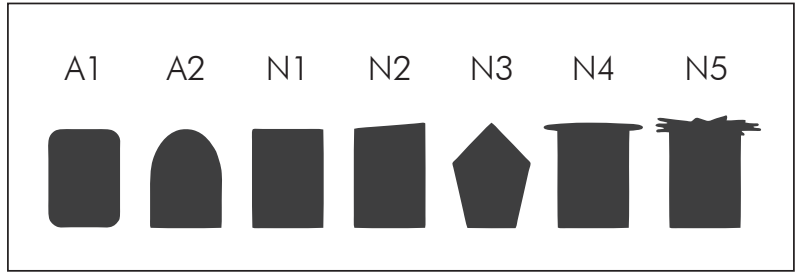

Figure 2 - Classification of the bristle-tip geometry in two groups. Groups A and N represent acceptable and non-acceptable rounding, respectively.

The significance level was defined as $p \leq 0.05$.

\section{Results \\ Bracket bond strength}

No significant difference was observed for the mean bond strength between Groups 1 (90.60 kgf/ $\left.\mathrm{cm}^{2}\right), 2\left(90.89 \mathrm{kgf} / \mathrm{cm}^{2}\right)$, and $3\left(90.18 \mathrm{kgf} / \mathrm{cm}^{2}\right)$. The bristle wear index (WI) was increased for both toothbrushes (Groups 2 and 3) after completion of the 20,000 brushing cycles.

\section{Bristle wear and assessment of bristle tips}

The Oral B Indicator 35 toothbrush had a more acceptable bristle tip morphology before brushing than the Colgate $360^{\circ}$ toothbrush, but the Colgate brush showed a more acceptable bristle tip morphology than the Oral B Indicator 35 after brushing. Within Groups 2 and 3, the bristle tip morphology before brushing was more acceptable than that after 

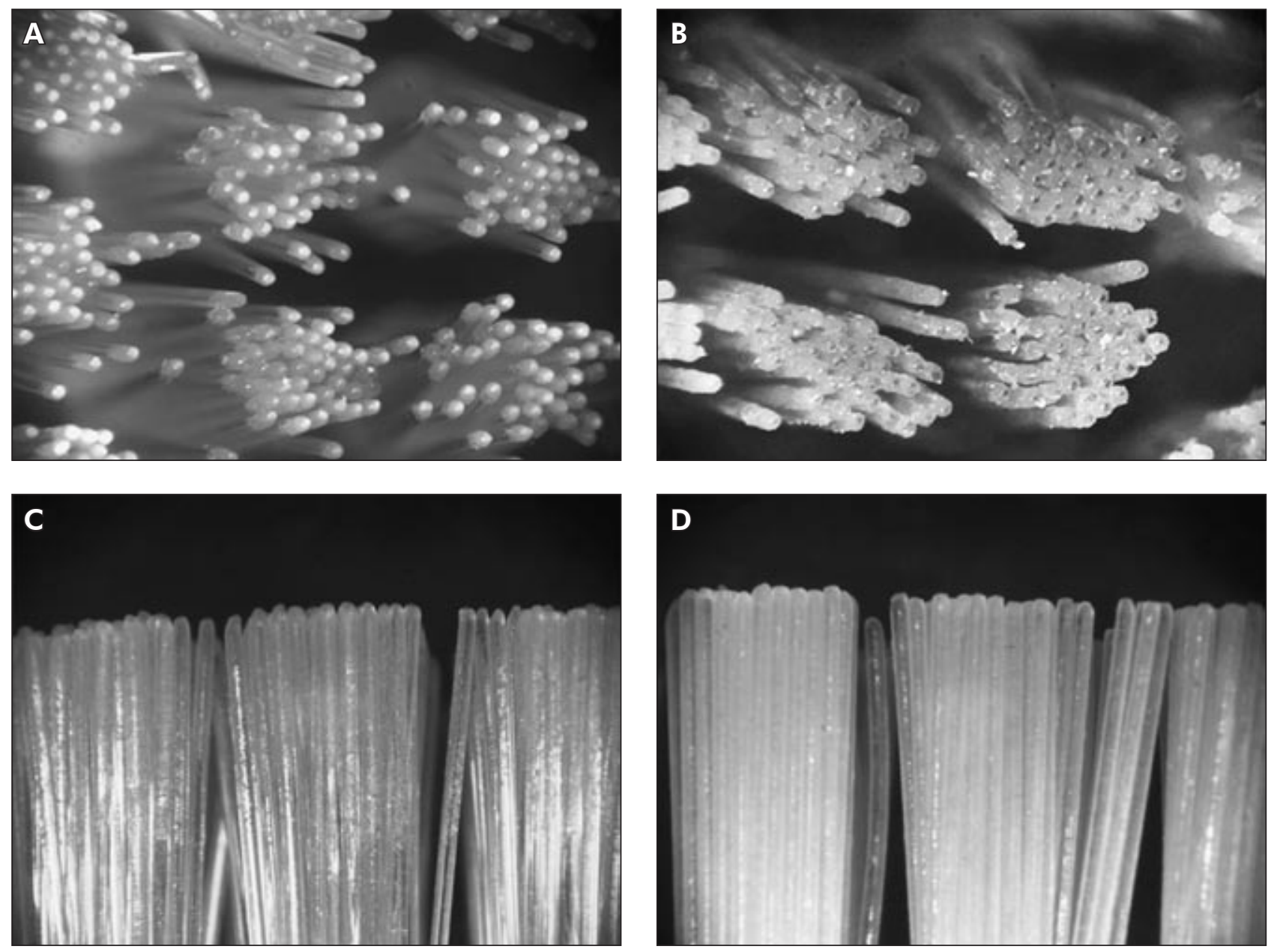

Figure 3 - Upper and side views of the Oral B Indicator 35 toothbrush before and after brushing cycles. (A) Upper view before brushing and demonstrating score A1. (B) Upper view after brushing and demonstrating score N5. (C) Side view before brushing and demonstrating score Al. (D) Side view after brushing and demonstrating score N2. (20 X)

brushing for both toothbrushes. For the Oral B Indicator 35 toothbrush, brushing worsened the central (Figures 3A, B) and side (Figures 3C, D) bristle tips. For the Colgate $360^{\circ}$ toothbrush, brushing worsened the central bristles (Figures 4A, B) but not the side bristles (Figures 4C, D).

\section{Discussion}

The Colgate $360^{\circ}$ toothbrush is designed to promote good hygiene, regardless of the brushing technique used. This toothbrush has different bristle sizes that facilitate biofilm removal in the interproximal region, rubber cups for prophylaxis, and a tongue cleanser to remove tongue coating. ${ }^{15}$ These characteristics have been suggested to explain its efficacy compared with conventional toothbrushes in reducing plaque indices and gingival inflammation $^{16,17}$ These benefits would justify the prescription of this toothbrush for orthodontic patients. However, the removal of plaque and pigments requires substantial frictional forces ${ }^{18}$ that could interfere with bond strength, resulting in bracket detachment. ${ }^{7}$

We found that the Colgate $360^{\circ}$ toothbrush did not affect the bonding of orthodontic brackets to the teeth compared to the Oral B Indicator 35. Hansen et al. ${ }^{7}$ (1999) assessed the bond strength of metal orthodontic brackets by simulating two years of brushing using conventional electric (Interplak ${ }^{\circledR}$ ) and sonic toothbrushes (Sonicare ${ }^{\circledR}$ ). Although these authors found a significant difference between the bond strengths of the control $\left(125.4 \mathrm{kgf} / \mathrm{cm}^{2}\right)$ and sonic toothbrush $\left(79.7 \mathrm{kgf} / \mathrm{cm}^{2}\right)$ groups, no differ- 

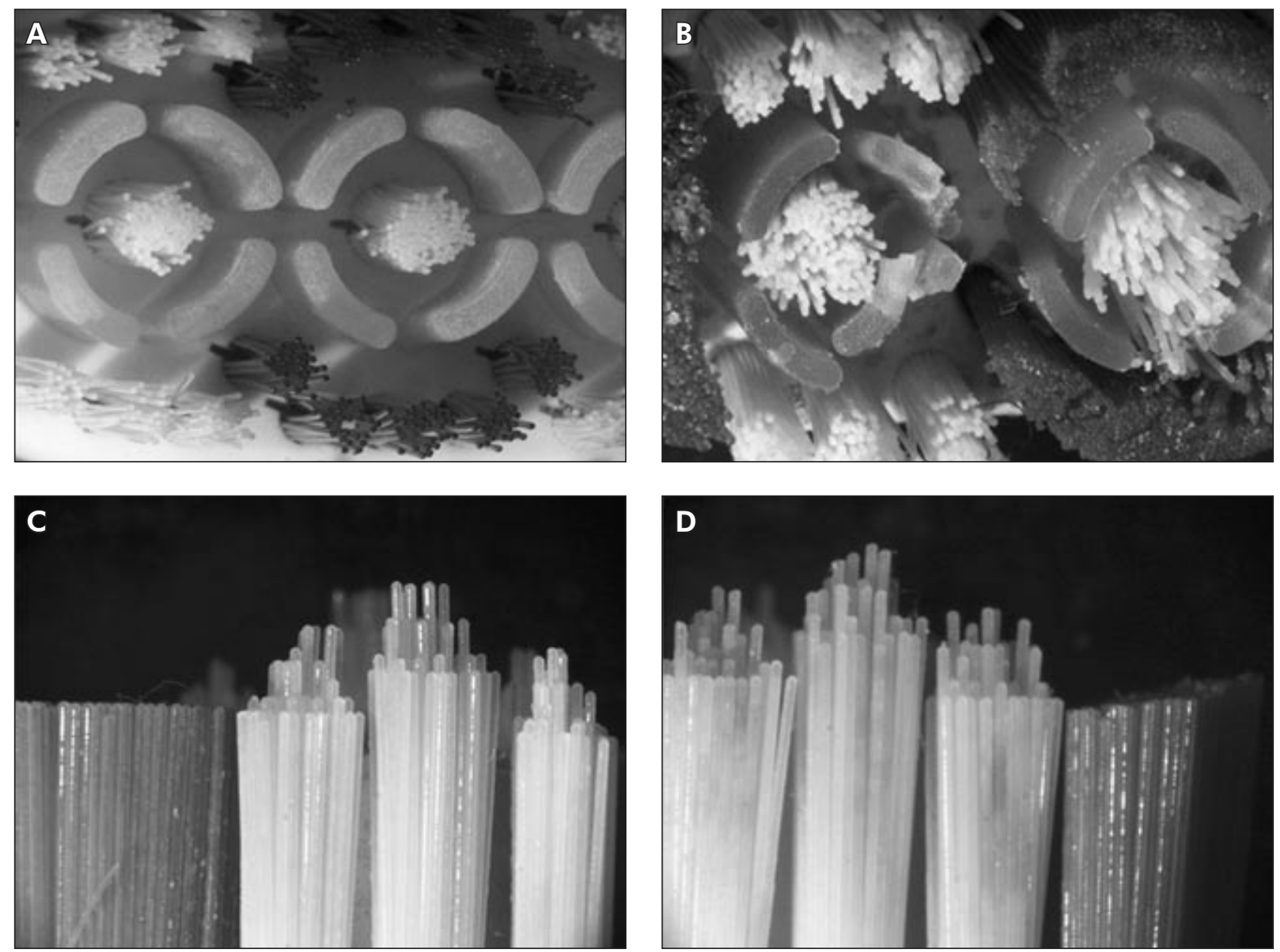

Figure 4 - Upper and side views of the Colgate $360^{\circ}$ toothbrush before and after brushing cycles. (A) Upper view before brushing and demonstrating score A1. (B) Upper view after brushing and demonstrating score N5. (C) Side view before brushing and demonstrating score Al. (D) Side view after brushing and demonstrating score Al. (20 X).

ence was found between the electric toothbrush group $\left(107.5 \mathrm{kgf} / \mathrm{cm}^{2}\right)$ and the sonic toothbrush or control group. Therefore, it was unclear whether the difference in bracket bonding was mainly due to mechanical forces or to the action of the sonic waves transmitted by the toothbrushes.

In the present study, significant bristle wear was verified after brushing the test specimens. The orthodontic bracket is a mechanical barrier that complicates oral hygiene, increases toothbrush friction and wear. It is recommended that the toothbrush be replaced whenever any sign of bristle wear is identified, or every 2-3 months, ${ }^{12}$ based on in vitro ${ }^{19}$ and in vivo ${ }^{8}$ studies showing that less plaque is removed by worn toothbrushes when compared with new brushes. However, several studies have demonstrat- ed no statistical differences in biofilm removal between new and worn toothbrushes. . $^{50-22}$ These studies indicate that other factors, such as the brushing time, brushing force, and motivation of the patient, are as important as the bristle integrity during oral hygiene. ${ }^{21}$

The quality of the rounded ends of the bristles is an important factor in protecting dental and gingival tissues. Round-tipped bristles are related to lower incidences of dental abrasions and gingival recessions. ${ }^{10,11,23}$ Studies have shown a deficiency in bristle tip standardization in many toothbrushes available on the market. ${ }^{24-26}$ In the present study, the Oral B Indicator 35 showed more acceptable bristle tip morphology than the Colgate $360^{\circ}$ before brushing. After brushing, the two toothbrushes showed 
a general worsening with regard to bristle tip morphology, with the Colgate $360^{\circ}$ having a better bristle tip morphology than the Oral B Indicator 35. This difference was due to the worsened morphology of the side bristles of the Oral B Indicator 35. The side bristles of the Colgate $360^{\circ}$ are of different sizes, and the shorter bristles would have less contact with the test specimen.

An optical microscope was used to assess the bristle tips. Other studies have assessed bristle tips using stereoscopy ${ }^{24,25}$ or scanning electron microscopy (SEM). ${ }^{26,27}$ Although both instruments have shown to be adequate, the bristles can become deformed during the metallization process required for SEM evaluation. ${ }^{25}$ This event does not occur when stereoscopy or optical microscopy is used.

The results of this research should be interpreted with caution due to some limitations. Toothbrushes are not commonly used for 24 months, as was the case in our study. This fact exacerbated the amount of trimming on both brushes. Standardization of the brushing force at $200 \mathrm{~N}$ is another limitation. The brushing force applied by orthodontic patients is very variable (range: 94-400 $\mathrm{N}^{28}$, mean: 250$300 \mathrm{~N}^{29}$ ). Thus, our results represent an average estimate, and are not representative of patients who

\section{References}

1. Haffajee AD, Cugini MA, Diabart S, Smith C, Kent RL, Socransky SS. The effect of SRP on the clinical and microbiological parameters of periodontal diseases. J Clin Periodontol. 1997 May;24(5):324-34.

2. Boyd RL, Baumrind S . Periodontal considerations in the use of bonds or bands on molars in adolescents and adults. Angle Orthod. 1992 Summer;62(2):117-26.

3. Rafe Z, Vardimon A, Ashkenazi M. Comparative study of 3 types of toothbrushes in patients with fixed orthodontic appliances. Am J Orthod Dentofacial Orthop. 2006 Jul;130(1):925.

4. Bishara SE, VonWaid L, Laffoon JF, Warren JJ . The effect of repeated bonding on the shear bond strength of a composite resin orthodontic adhesive. Angle Orthod. 2000 Dec;70(6):435-41.

5. van Palenstein Helderman WH, Kyaing MM, Aung MT, Soe W, Rosema NA, van der Weijden GA, et al. Plaque removal by young children using old and new toothbrushes. J Dent Res. 2006 Dec;85(12):1138-42. apply extremely low or high brushing forces.

\section{Conclusion}

Based on the methodology applied in this study, it was concluded that:

1. The Colgate $360^{\circ}$ and Oral B Indicator 35 toothbrushes did not decrease the bracket bond strength.

2. There was evident bristle wear of the Oral B Indicator 35 and Colgate $360^{\circ}$ toothbrushes after brushing. However, more studies with patients undergoing orthodontic treatment are necessary to assess whether this wear influences the mechanical plaque control.

3. The Colgate $360^{\circ}$ toothbrush showed a better bristle tip morphology after brushing than the Oral B Indicator 35. This was because the side bristles of the Colgate $360^{\circ}$ have different sizes, and the shorter bristles have less contact with the test specimen.

\section{Acknowledgements}

This study was supported by CAPES (Coordenação de Aperfeiçoamento de Pessoal de Nível Superior).

6. Bishara SE, Ostby AW, Laffoon JF, Warren J . Shear bond strength comparison of two adhesive systems following thermocycling. A new self-etch primer and a resin-modified glass ionomer. Angle Orthod. 2007 Mar;77(2):337-41.

7. Hansen PA, Killoy W, Masterson K. Effect of brushing with sonic and counterotational toothbrushes on the bond strength of orthodontic brackets. Am J Orthod Dentofacial Orthop. 1999 Jan;115(1):55-60.

8. Glaze PM, Wade AB. Toothbrush age and wear as it relates to plaque control. J Clin Periodontol. 1986 Jan;13(1):52-6.

9. Warren P, Jacobs D, Low M, Charter B, King D. A clinical investigation in to the effect of toothbrush wear on efficacy. J Clin Dent. 2002;13(3):119-24.

10. Silverstone LM, Featherstone MJ. Examination of end rounding pattern of toothbrush bristles using scanning electron microscopy: A comparison of eight toothbrush types. Gerodontics. $1988 \mathrm{Apr}$ 4(2):45-62. 
11. Radentz WH, Barnes GP, Cutright DE. A survey of factors possibly associated with cervical abrasion of tooth surface. $\mathrm{J}$ Periodontol. 1976 Mar;47(3):148-54

12. Claydon NC. Current concepts in toothbrushing and interdental cleaning. Periodontol 2000. 2008;48:10-22.

13. Tanoue N, Matsumura H, Atsuta M . Analysis of composite type and different sources of polymerization light on in vitro toothbrush/dentifrice abrasion resistance. J Dent. $2000 \mathrm{Jul} ; 28(5): 355-9$.

14. Rawls HR, Mywayi-Tulloch NJ, Casella R, Cosgrove R. The measurement of toothbrush wear. J Dent Res. 1989 Dec;68(12):1781-5.

15. Hohlbein DJ, Williams MI, Mintel TE . Driving toothbrush innovation through a cross-functional development team. Compend Contin Educ Dent. 2004 Oct;25(10 Suppl 2):7-11.

16. Nathoo S, Chaknis P, Petrone M, DeVizio W, Volpe AR . A clinical comparison of the gingivitis reduction and plaque removal efficacy of a new manual toothbrush. Compend Contin Educ Dent. 2004 Oct;25(10 Suppl 2):37-45.

17. Mankodi S, Wachs GN, Petrone DM, Chaknis P, Petrone M, DeVizio W, et al. Comparison of the clinical efficacy of a new manual toothbrush on gingivitis reduction and plaque removal. Compend Contin Educ Dent. 2004 Oct;25(10 Suppl 2):28-36.

18. Dyer D, MacDonald E, Newcombe RG, Scratcher C, Ley F, Addy M. Abrasion and stain removal by different manual toothbrushes and brush actions:studies in vitro. J Clin Periodontol. 2001 Feb;28(2):121-7.

19. Kreifeldt J, Hill P, Calisti L. A systematic study of the plaque removal efficiency of worn toothbrushes. J Dent Res. 1980 Dec;59(12):2047-55.
20. Hogan LME, Daly CG, Curtis BH . Comparison of new and 3 -month-old brush heads in the removal of plaque using a powered toothbrush. J Clin Periodontol. 2007 Feb;34(2):1306.

21. Sforza NM, Rimondini L, di Menna F, Camorali C. Plaque removal by worn toothbrush. J Clin Periodontol. 2000 Mar;27(3):212-6.

22. Tan E, Daly C. Comparison of new and 3-month-old toothbrushes in plaque removal. J Clin Periodontol. 2002 Jul;29(7):645-50.

23. Dyer D, Addy M, Newcombe RG. Studies in vitro of abrasion by different manual toothbrush heads and a standard toothpaste. J Clin Periodontol. 2000 Feb;27(2):99-103.

24. Checchi L, Minguzzi S, Franchi M, Forteleoni G. Toothbrush filaments end-rounding: stereomicroscope analysis. J Clin Periodontol. 2001 Apr;28(4):360-4.

25. Checchi L, Farina E, Felice P, Montevecchi M. The electric toothbrush: analysis of filaments under stereomicroscope. J Clin Periodontol. 2004 Aug;31(8):639-42.

26. Jung M, Soydan N, Rubbert F, Wetzel WE. Quality of bristle end-rounding on replaceable heads of powered toothbrushes. J Clin Periodontol. 2005 Jun;32(6):604-9.

27. Meyer-Lueckel H, Rieben AS, Kielbassa AM. Filament endrounding quality in electric toothbrushes. J Clin Periodontol. 2005 Jan;32(1):29-32.

28. White L. Toothbrusing pressures of orthodontic patients. Am J Orthod. 1983 Feb;83(2):109-13.

29. Heasman PA, Macgregor IDM, Wilson Z, Kelly PJ. Toothbrushing forces in children with fixed orthodontic appliances. Br J Orthod. 1998 Aug;25(3):187-90. 